\title{
Carlos Rincón, editor de Hernando Téllez y Hernando Valencia GoelKel*
}

\author{
Carlos Rincón, editor of Hernando \\ Téllez and Hernando Valencia Goelkel
}

Jonathan Beltrán Alvarado ${ }^{1}$

\begin{abstract}
* Artículo derivado de una ponencia presentada en el homenaje a Carlos Rincón Rutas de la critica cultural y literaria en Colombia y América Latina, celebrado el 31 de octubre de 2019. Agradezco a los profesores Carlos Arturo López, Juan Pablo Garavito, Juan Camilo Betancur y Alicia Natali Chamorro por las valiosas discusiones del grupo de investigación "Una historia de la filosofía escrita en el actual territorio colombiano".
\end{abstract}

Cómo citar este artículo: Beltrán Alvarado, J. (2021). Carlos Rincón, editor de Hernando Téllez y Hernando Valencia Goelkel. Estudios de Literatura Colombiana 48, pp. 77-94. DOI: https://doi.org/10.17533/udea.elc.n48a04

1 https://orcid.org/0000-0002-8637-4577 jonathan.beltran@javeriana.edu.co/ je.beltrana@uniandes.edu.co

Fundación Colegio Santa María, Colombia

Editores: Andrés Vergara Aguirre, Christian Benavides Martínez, Valentina Noreña Gómez

Recibido: 15.08 .2020

Aprobado: 28.10.2020

Publicado: 18.12 .2020

Copyright: (2021 Estudios de Literatura Colombiana. Este es un artículo de acceso abierto distribuido bajo los términos de la Licencia Creative Commons AtribuciónNo comercial - Compartir igual 4.0 Internacional
Resumen: este artículo ofrece una comprensión histórica de las metáforas utilizadas por Carlos Rincón en su labor de crítico y editor de la obra de Hernando Téllez y Hernando Valencia Goelkel. Se revisan los tomos publicados por la editorial del Instituto Caro y Cuervo: Crítica literaria I 19361947 (2016), II 1948-1956 (2017) y III 1957-1967 (2017), de Hernando Téllez y Crítica literaria Tomo I 1955-1976 (2018) y Tomo II 1977-1997 (2018), de Hernando Valencia Goelkel. La discusión está centrada en cómo y por qué presenta Rincón a Téllez y a Valencia como pilares de la crítica literaria colombiana de siglo xx.

Palabras clave: Carlos Rincón; Hernando Téllez; Hernando Valencia Goelkel; Instituto Caro y Cuervo; crítica literaria.

Abstract: This article offers a historical understanding of the metaphors used by Carlos Rincón in his rol as a critic and editor of the work of Hernando Téllez and Hernando Valencia Goelkel. The volumes published by the Instituto Caro y Cuervo reviewed are: Crítica literaria I 1936-1947 (2016), II 1948-1956 (2017), and III 1957-1967 (2017), by Hernando Téllez, and Crítica literaria Tomo I 1955-1976 (2018), and Tomo II 1977-1997 (2018), by Hernando Valencia Goelkel. The discussion is centered on how and why Rincón presents Téllez and Valencia as pillars of twentieth-century Colombian literary criticism.

Keywords: Carlos Rincón; Hernando Téllez; Hernando Valencia Goelkel; Instituto Caro y Cuervo; literary criticism. 


\section{Introducción}

Sobre el palimpsesto de la historia de la crítica literaria nacional aparecen cada cierto tiempo las siguientes palabras: "no hay crítica ni críticos en Colombia". Desde la academia (Montoya, 2007) o la opinión pública (Castaño, 2017), siempre alguien marca nuevamente el pergamino con el diagnóstico de Hernando Téllez comentado por Baldomero Sanín Cano en el artículo "La crítica en Colombia", carta publicada el 13 de octubre de 1946 en el periódico El Tiempo. Es evidente que la oración debe a su propio filo el haber atravesado décadas sin mayor esfuerzo. Menos notorias han sido, quizás, otras palabras presentes en la misma carta. Se trata de un pasaje que aparece hacia el final del escrito en el que Sanín Cano pasa revista a las tareas del crítico que considera más valiosas: "su labor más noble es comprender, pero se ocupa también en investigar orígenes, aquilatar influencias, sorprender olvidos y fijar escuelas. Su más noble función, ejemplo Brandes, es buscar en la obra de un autor al hombre que la ha escrito" (Sanín Cano, 1987, p. 346).

Entre 2016 y 2018, el Instituto Caro y Cuervo publicó dos proyectos editoriales de especial importancia para la historia de la crítica literaria en el país. Se trata de los libros Crítica literaria I 1936-1947 (2016), Crítica literaria II 1948-1956 (2017) y Crítica literaria III 1957-1967 (2017), de Hernando Téllez, y Crítica literaria Tomo I 1955-1976 (2018) y Critica literaria Tomo II 1977-1997 (2018) de Hernando Valencia Goelkel. El coordinador de estos proyectos fue Carlos Rincón, cuya faceta de editor, asaz menos estudiada, se suma a sus trabajos ampliamente reconocidos de docencia, traducción y crítica de la cultura.

El proyecto sobresale no solo por la eminencia de los críticos elegidos, sino por su magnitud como empresa editorial. El dispendioso trabajo de establecimiento de la edición pudo completarse gracias a la participación y los préstamos internacionales de la Biblioteca Nacional de México, la Biblioteca Nacional de Buenos Aires, la Biblioteca Nacional de París, la Biblioteca de Filología de la Universidad Libre de Berlín, la Biblioteca Estatal de Berlín y la biblioteca del Instituto Iberoamericano de Patrimonio Cultural Prusiano (Téllez, 2016, p. 465). Las notas agregan valiosas referencias y acompañan los artículos con la silenciosa presencia de la "gran biblioteca personal de Hernando Téllez" (p. 465) y de medio siglo de hallazgos en torno a la obra de Valencia Goelkel (2018b, p. 539). Fundamental es que cada tomo es introducido por un estudio en el que Rincón, fiel al oficio crítico preconizado por Sanín 
Cano, investiga orígenes y aquilata influencias, pero sobre todo, ofrece al lector su encuentro personal de Hernando Téllez y Hernando Valencia Goelkel.

El presente artículo, basado en la actividad de Rincón como editor, se suma al proceso de asimilación de su obra crítica que sucede ya en estudios como "Carlos Rincón y la crítica de la voluntad de verdad. Una pragmática de la crítica literaria” (2012), de Alejandro Sánchez Lopera, cuya hipótesis será retomada más adelante, y "La crítica cultural y literaria de vanguardia de Carlos Rincón" (2019), de Juan David Escobar, que historiza los problemas críticos relevantes en su obra entre 1978 y 1999. Ahora bien, el carácter de la obra de Rincón, prolífico y generoso en conexiones significativas, requiere que la ponderación de su legado se haga tratando de mantener unidas sus diferentes intervenciones en el campo cultural.

El camino para integrar obra crítica con trabajo editorial se encuentra figurado en el comentario a la edición del segundo tomo de la obra crítica de Hernando Valencia Goelkel. Allí, Rincón explica que la recolección de los materiales comenzó de manera espontánea a comienzos de los años setenta, fue progresivamente sistematizada en la segunda mitad de los años ochenta y, tras la caída del muro de Berlín y la llegada de Jean Franco al Zentralinstitut Lateinamerika en calidad de profesora visitante, ordenada digitalmente conforme a núcleos temáticos. De este proyecto habría surgido el coloquio Celebraciones y lecturas: La crítica literaria en Latinoamérica, cuyos resultados se recogieron en el número doble 14-15 de Nuevo Texto Crítico (junio de 1994-junio de 1995), en una publicación dirigida por Jorge Ruffinelli en Stanford University (Valencia Goelkel, 2018b, pp. 539-540). Algo puede colegirse: el trabajo editorial de Carlos Rincón puede ser pensado como una vía más de elaboración del archivo que fue construyendo en su ejercicio como crítico, docente e investigador. Además, importa resaltar que, en una disciplina constantemente amenazada por la costumbre de la reflexión solitaria, la tendencia de Rincón a trabajar en equipos le permitió formar las redes necesarias para convertir sus pesquisas en proyectos de gran escala.

Esta forma de concebir los vínculos internos entra la investigación, la crítica y la edición tiene por ejemplo libros como Entre el olvido y el recuerdo: iconos, lugares de memoria y cánones de la bistoria y la literatura en Colombia (2010), libro editado junto con Sarah González Keelan y Liliana Gómez con ocasión del Bicentenario de la Declaración de Independencia; Francisco Posada, Textos reunidos (2014), cuyo trabajo documental con la obra del filósofo colombiano lo convierte en el antecedente directo 
de las obras aquí estudiadas; El juicio televisivo de la novela de Isaacs, los ecos y el dolor de lo que pudo haber sido y no fue (2017), libro que reúne distintos ensayos sobre la novela Maria (1867) de Jorge Isaacs y en el que se incluye una divertida simulación de juicio escrita por Ernesto Cortés Ahumada.

Sin embargo, entre estas publicaciones destacan los tomos dedicados a Hernando Téllez y a Hernando Valencia Goelkel por el valor central que tienen en la historia de la crítica literaria colombiana. Por ser intelectuales vinculados a las revistas Mito y Eco y por haber participado activamente en la prensa, las publicaciones periódicas y los proyectos editoriales de su época, ambos tuvieron el raro mérito de influir en la valoración de las obras publicadas, crear públicos y orientar múltiples proyectos editoriales. Es claro que los volúmenes editados por Carlos Rincón permitirán avanzar en el conocimiento de las vidas de Téllez y Valencia Goelkel. De hecho, siguiendo la publicación del Instituto Caro y Cuervo, un excelente perfil biográfico de Hernando Téllez fue publicado recientemente por Sarah González Keelan en el volumen LXXXIV (2018) de la Revista Iberoamericana con el título "Hernando Téllez (1908-1966): Apuntes para una biografía”. Allí puede rastrearse cómo su formación en el oficio periodístico y su educación atenta a la cultura francesa cimentó las bases de su vocación literaria. Sobre Hernando Valencia Goelkel puede consultarse el perfil hecho por Nicolás Suescún para el periódico Ciudad Viva (Suescún, 2005), pero los ensayos publicados por el propio Rincón en la introducción de los volúmenes son el trabajo más completo y relevante publicado hasta ahora a propósito de la vida del autor.

Hasta aquí, con el propósito de situarnos en un terreno común, hemos hecho algunas aclaraciones sobre el trabajo de Carlos Rincón como editor y las figuras de Hernando Téllez y Hernando Valencia Goelkel como críticos. En adelante, este estudio se propone responder, principalmente, dos preguntas. En primer lugar: ¿qué criterios metodológicos guiaron las decisiones de Rincón en el proceso de establecimiento, introducción y anotación de la obra de Téllez y Valencia? Esta pregunta importa porque nos permitirá establecer un vínculo significativo entre el trabajo como editor de Carlos Rincón y su escrito "Memoria y nación: una introducción” (2010). La segunda pregunta que habrá de guiar la reflexión es la siguiente: ¿cuáles de los problemas presentados en los estudios introductorios resultan esenciales para situar a estas dos figuras en el panorama de la crítica literaria en Colombia desde 1936 hasta 1997? Esta pregunta nos permitirá ir y volver entre los estudios de Rincón y 
la vida y la época de Téllez y Valencia, cumpliendo así el postulado crítico de Sanín Cano según el cual una de las tareas es buscar al hombre.

La hipótesis de esta revisión podría enunciarse de la siguiente manera: la compleja obra crítica y editorial de Rincón anuda amistades, pasiones personales, erudición, rigor de experto y gusto de amante de la literatura, pero bien puede decirse que, en conjunto, su propósito principal al publicar este trabajo fue establecer a Hernando Téllez y a Hernando Valencia Goelkel, junto con el ya consagrado Baldomero Sanín Cano, como los principales referentes de la crítica literaria colombiana de siglo xx. Para lograrlo, recurre a un conjunto de metáforas topográficas que espacializan la obra de los críticos editados y le permiten realizar las operaciones de selección, edición y montaje que deberían tener como resultado el fijar a estos críticos en el centro de la historia de la literatura colombiana de siglo xx.

Antes de entrar a los volúmenes vale la pena preguntarse: con tanta información valiosa sobre el proceso histórico y los orígenes e influencias de estos dos críticos, ¿por qué fijarse especialmente en las metáforas? Pues bien, basta con revisar "Memoria y nación: una introducción" para ver hasta qué punto adhiere Rincón a la tesis de Harald Weinrich: "no podemos pensar un objeto como la Memoria sin recurrir a las metáforas" (citado en Rincón, 2010, p. 27). De hecho, para Rincón la memoria es una "gran máquina productora de metáforas" (p. 29). Es en este sentido que recupera la idea de Douwe Draaisma según la cual concepciones sobre el recuerdo son alimentadas por los procedimientos y técnicas disponibles para conservar y reproducir información (p. 29). ¿Cuál es la consecuencia? Que el recuerdo, lejos de ser una cosa opaca e inamovible, está siempre abierto a su transformación.

Tal síntesis transformadora y creativa es la que se hace posible en la elaboración metafórica. Rincón, presto a establecer matices semánticos y a dibujar la historicidad de las metáforas, pasa revista a distintos tipos: aquellas propias de la Edad Media que se refieren a la memoria como un cofre en el que se almacena o se extrae (p. 26), las que surgieron al abrigo del siglo xix y se caracterizaron por espacializar la memoria en un laberinto o en una cicatriz que permanece (p. 27), las metáforas arquitectónicas y sus juegos con el tiempo y el espacio que desde la antigüedad romana configuraron el ars memoriae...

En todo caso, como bien señala Sánchez Lopera (2012), Carlos Rincón, como pensador adverso al refugio estable de las esencias, se caracterizó por hacer una crítica 
basada en una noción de la verdad como operaciones (p. 82), en particular, de operaciones entre hechos empíricos. Pues bien, si Rincón reconoce que la "memoria fotográfica" fue el modelo tecnológico por excelencia para hacer operaciones sobre la memoria desde principios del siglo $\mathrm{xx}$, no hay que sorprenderse cuando, puesto a organizar la crítica literaria colombiana de esta época, se decide a hacer un montaje de metáforas con el propósito de reproducir la continuidad entre diversos proyectos críticos. En el fondo, se trata de seguir el clásico mandato de Baldomero Sanín Cano al "sorprender olvidos y fijar escuelas"; la diferencia estriba en que, para hacerlo, la operación utilizada es un montaje de metáforas que Rincón aprovecha tanto para ordenar la inmensidad de su archivo como para decantarse por una "escuela" de críticos: aquellos que se caracterizaron por tener una intervención pedagógica de efecto pluralista en la sociedad.

\section{Hernando Téllez}

\section{Las metáforas que guían la práctica editorial: el trayecto y la piedra miliar}

Como se ha dicho anteriormente, la aproximación de Carlos Rincón a las obras de Téllez y Valencia está mediada por un conjunto de metáforas que, por un lado, condensan su saber experto de crítico y editor y, por otro, muestran el valor histórico de la obra crítica de estos autores: los futuros posibles abiertos por la afirmación valorativa y el cuidado de las huellas del pasado hecho en el ordenamiento de los archivos. Las metáforas a partir de las cuales se aproxima a la obra de Valencia (torre, territorio y triunvirato) serán comentadas en su momento. Por ahora, comencemos con aquellas que, habiendo sido propuestas para abordar la obra de Téllez, sirven para formarse una idea del valor patrimonial de las obras publicadas por el Instituto Caro y Cuervo: trayecto y piedra miliar.

El término "trayecto" aúna las ideas de espacialidad y de secuencia (Téllez, 2017a, p. 17). La imagen espacial del trayecto surge al imaginar la distancia entre dos puntos y las posibilidades de "zarpar", "dejar huella" y "cruzar límites". Ahora bien, no interesa que estos dos puntos puedan ser unidos con una línea y tampoco que esa línea sea, a su vez, un número infinito de puntos, sino que cada uno de ellos pueda ser pensado como una huella, pues entonces el problema de la espacialidad del trayecto se convierte en un objeto de investigación que cabe en lo que Carlo Ginzburg denominó el paradigma indiciario: el anclaje epistemológico de una práctica propia de cazadores, médicos e historiadores que buscan restituir el todo a partir de la parte 
-el animal a partir de su aroma, su huella o su sudor; la enfermedad a partir de sus síntomas- (Ginzburg, 1999, p. 144). Por ahora, podemos tener una idea clara del trayecto de Téllez y de Valencia, pero ¿cuáles son los puntos o las líneas en este caso, cuáles los puertos en los que se zarpa, cuáles las huellas y cuáles las fronteras?

El término "trayecto" incluye, además, la idea de secuencia. Esta es una idea de temporalidad "poseedora de cierta homogeneidad relativa" (Téllez, 2017a, p. 46), es decir, una temporalidad ordenada. Por ahora, la idea de trayecto nos presenta puntos en el espacio cuya aparición es regular. Teniendo esto presente, es más sencillo comprender por qué resulta significativa para Rincón la imagen de las piedras miliares, columnas que los romanos construían en sus caminos cada mil pasos para marcar el territorio y señalar la distancia entre Roma y cualquier otro punto del Imperio. Si unimos las dos imágenes, resulta: definir el trayecto de Téllez y Valencia exige, para el constructor del camino, ubicar sus huellas, que en este caso serán sus textos críticos, y ordenarlas en el tiempo con un criterio de periodicidad determinado. Sobre este camino tendrán que señalarse hitos o erigirse piedras miliares que funcionen como enclaves que produzcan la idea de secuencia.

Pero el objetivo anterior se estrella con la realidad de los archivos, pues en ambos casos puede decirse que, por modestia de los autores o descuido de los contemporáneos, muchos de sus textos quedaron dispersos en diferentes diarios, semanarios, revistas y algunos pocos libros o antologías. Así pues, la construcción del camino es a la vez la invención de una obra, o la síntesis de los papeles dispersos.

Pues bien, como experto constructor de caminos, Rincón se rige por dos preguntas rectoras: primero, “¿con qué criterios puede otorgársele el estatus de piedras miliares a algunos de sus escritos de crítica literaria para conseguir establecer de ese modo un corpus minimalista que permita marcar hitos de su trayecto?" (Téllez, 2017a, p. 13) y, segundo, “¿qué posibilidades puede y debe ofrecer ese corpus, así sea de manera muy general, en la relación entre labor crítica literaria, transmisión cultural e historia personal y colectiva?” (p. 13). Sus respuestas revelan, tanto como las preguntas, los criterios metodológicos que guiaron la preparación de estos volúmenes patrimoniales. La primera respuesta es palmaria: el corpus minimalista puede erigirse por medio de una aproximación histórica a los archivos de Téllez y Valencia. La segunda respuesta, que también arroja luces a propósito del lugar de este trabajo para la historia de la crítica literaria en Colombia, es la siguiente: la posibilidad que se abre al 
contar con estos volúmenes reunidos es la de pensar estos proyectos críticos en conjunto, reflexión de la que surgen los problemas que serán planteados a continuación.

\section{El crítico pedagogo}

Ahora, vale la pena preguntarse: ¿cuál fue el fundamento del ejercicio crítico de Hernando Téllez? Escuchemos a Rincón: "como intelectual secular y democrático cuyo propósito clave resulta ser enseñar a leer, Hernando Téllez fue el crítico literario moderno por excelencia en Colombia" (en Téllez, 2017a, p. 16). Para darle contenido a esta asociación entre pedagogía, democracia y modernidad resulta de gran provecho la descripción de las circunstancias que, en los años de la República Liberal (1930-1946), dieron significado a los términos "Extensión cultural".

Según Renán Silva, uno de los proyectos más ambiciosos de la República Liberal fue la transformación de la institucionalidad y la infraestructura estatal en educación con arreglo a un propósito general: ampliar la irradiación del Estado colombiano incluyendo, dando participación en él a la inmensa mayoría de personas que integraban el país rural. Como parte de este programa se realizó un intenso ejercicio de revisión de lo que hasta el momento había sido la tarea del Ministerio de Instrucción y Salubridad Pública, que tal fue su nombre antes de llamarse Ministerio de Educación. A propósito, Silva trae a colación el diagnóstico hecho por Eliseo Arango, en julio de 1930, sobre el estado de la institución a su llegada: "es necesario que el país no se siga engañando con una oficina que lleva el nombre de Ministerio de Educación. Lo que principalmente existe es un despacho encargado de suministrar recursos para las leproserías, caridad y beneficencia, y que tiene modestos aportes para la enseñanza” (Silva, 2005, p. 155). Dicha situación habría de cambiar paulatinamente gracias a programas como las Misiones Culturales (o "ambulantes"), con las que se difundieron libros y bibliotecas en todo el país en una actividad que resultaba complementaria al Censo Cultural, encuesta que se realizó por la misma época (1933-1934) y que buscaba recopilar información a propósito de:

Los fenómenos significativos de la vida de las comunidades locales, tanto en el plano de la "civilización material" (condiciones de vida y de producción agrícola y ganadera, mercados, carreteras, enfermedades de hombres y animales, infraestructuras materiales en relación con agua, luz, telégrafo, etc.) como en el plano de la cultura intelectual (escuelas, bibliotecas, número de volúmenes existentes, salas culturales, etc.) (Silva, 2005, p. I7の). 
La pedagogía fue, entonces, una continuación de la política por otros medios: se buscaba extender la infraestructura del Estado promoviendo, a su vez, la consolidación de una idea de ciudadanía fundamentada en valores modernos (libertad de consciencia) afín a los principios de una democracia liberal.

En síntesis, el cambio más notable que puede señalarse en la República Liberal con respecto a la política cultural de los anteriores gobiernos conservadores es que su programa desplaza las relaciones entre Gobierno y gobernados desde aquellas que pueden darse en un Estado cifrado por la autoridad de la gramática hasta aquellas que se dan en un Estado que se dirige abiertamente a la población, por un lado, mediante la masificación y reproducción en las áreas rurales de las prácticas culturales urbanas; y, por otro, a partir de un interés confeso en la cultura popular. En este marco pueden situarse las palabras de Darío Achury Valenzuela, quien al frente del Ministerio de Educación decía en el año 1940:

Conviene, finalmente, insistir sobre un hecho singular que entraña en sí un desequilibrio que, de persistir, constituiría el principio de una crisis de la inteligencia entre nosotros. Se trata del impresionante contraste que se ha establecido, por una parte, entre el pueblo que ha sabido corresponder a todos los estímulos culturales con fervor y entusiasmo crecientes, y por otra, la frialdad, rayana en el escepticismo, que se ha apoderado de quienes deberían ser los naturales mentores y los guías intelectuales de aquel pueblo (citado en Silva, 2005, p. 185).

Dicho lo anterior sobre la vinculación entre pedagogía, modernidad y democracia, vale la pena señalar un punto más. Partiendo de la declaración de Achury puede constatarse que lo que para él significaba la responsabilidad de los intelectuales como consciencia crítica del pueblo no fue, en todo caso, exclusiva suya. Sanín Cano, eje del canon de la historia de la crítica literaria en el país, compartía una visión semejante que había tenido ocasión de enseñar a Hernando Téllez. Volvamos al ya citado "La crítica en Colombia", carta escrita por Sanín Cano a Téllez, quien, ocupando su lugar como aprendiz, lee que:

Tiene mucha enjundia su explicación de usted sobre las razones que en su sentir obran en este país sobre el espíritu y el desenvolvimiento de la literatura para que no haya críticos ni crítica. Usted dice que falta una tradición, y tiene razón. Falta una escuela de enseñanza humanista. La crítica aunque no se manifieste en libros o en crónicas hebdomarias y en revistas mensuales de sabias publicaciones existe conservada en la inteligencia y en el conocimiento de un cierto número de personas. La crítica no es propiamente una actividad sino un acervo de conocimientos, una disciplina, un cúmulo de ideas y sentimientos transmitido por una generación a otras (Sanín Cano, 1987, p. 345).

En algo estarían de acuerdo y es que la crítica literaria es una tarea que requiere de la inteligencia de cierto número de personas; más todavía en un país constantemente 
amenazado por la pobreza y el analfabetismo de las mayorías. No obstante, ¿qué tiene de moderno esta concepción elitista de la crítica literaria? Dos cosas: por una parte, la relación entre quien ejerce la disciplina crítica y sus lectores (que es pedagógica y no autoritaria); por otra, la responsabilidad del crítico en la creación de un público lector, que pasa por el análisis de las condiciones socioeconómicas que obstaculizan este proceso (no en vano advirtió hasta la saciedad Téllez que un óbice mayor a la profesionalización de la literatura era la carencia de medios materiales, la pobreza de la civilización física) (Téllez, 2017b, p. 37). Dos corolarios. Primero, la forma de esta relación entre intelectual y opinión pública es la que indica Rincón con el desplazamiento que hace Téllez de la autoridad del letrado señorial a la potestad del conocedor. Para dar plena fundamentación a este cambio, Rincón indaga la relación entre Téllez y Saint-Beuve (admirado y citado constantemente por Sanín Cano), y presenta a Téllez como lector de Thibaudet y atento seguidor de la Nouvelle Revue Française. Segundo, la constatación hecha por Sanín Cano de la carencia de una cultura humanística daba en el nervio del orgullo clásico que la memoria conservadora mantenía bajo la sombra de Caro y en la figura de personas como Félix Restrepo S. J. y José Manuel Rivas Sacconi.

El artículo “¿Pero hay una tradición humanista?” es una pieza especialmente relevante en este proceso de liquidación de los tesoros sentimentales de la generación del Centenario. El escrito de Téllez es una respuesta a un artículo de José María Restrepo Millán titulado “¿Qué hay de nuestra famosa tradición humanística?”, publicado el 22 de abril en El Tiempo, en el que el emérito filólogo y latinista lamentaba la pérdida de la tradición humanista "como consecuencia de la insensatez predominante en los programas de la enseñanza, como consecuencia de las alternativas políticas, como consecuencia de la improvisación, el confesionalismo y la baladronada de tipo sectario" (Téllez, 2017a, p. 61). Según Téllez, el humanismo colombiano es una "gentil contravención" (p. 64) a las condiciones históricas, pues "desciende del Olimpo para llegar a la escuela, a la universidad, a la plaza pública, a la calle, a la sociedad, al pueblo" (p. 62). Al representar las conquistas del humanismo a la luz del estado de la educación nacional no solo consigue producir un efecto de extravagancia, que resulta profundamente político si se tiene en cuenta la asociación atávica del humanismo a la Iglesia y al partido Conservador vía la figura de Miguel Antonio Caro, sino que pone una de las primeras cuentas en el rosario de escrúpulos Centenaristas. Tras constatar 
que, pese al detrimento general de la sociedad renovado al principio de la década, no podía afirmarse la existencia de una tradición en peligro, Téllez señala:

Pero el pueblo no tiene la culpa, repito. Como no la tiene de otras cosas, peores y más crueles y sangrientas que su devoción intelectual y sentimental por las cursilerías de un determinado escritor. Esa responsabilidad se halla en otras capas sociales, llamadas rectoras. Y si la debilidad, la flaqueza cultural de un país se puede demostrar, por ejemplo, con la abundancia de su analfabetismo y la inseguridad de su gusto literario, no es posible al mismo tiempo atribuirle una tradición humanística, porque una tradición supone una línea constante y continua de desarrollo... (p. 65).

El desplazamiento crítico, reservado para Téllez y su concepción pedagógica de la crítica, se observa con claridad si se tiene en cuenta cómo el saber letrado, insignia de los políticos de la Regeneración y los escritores de la llamada generación del Centenario, es resignificado como una marca vergonzante de inepcia directiva. El escrito de Téllez, hijo de uno de los años más violentos de La Violencia, presagia, como fue indicado anteriormente, el diagnóstico que algunos Centenaristas harán de su participación en el siglo: "López de Mesa escribió que su generación había sido 'una generación tocada de locura'. Laureano Gómez opinó: 'no son escasos ni afortunados los rastros que la Generación del Centenario deja”'(Henderson, 2006, p. 610).

\section{Hernando Valencia Goelkel}

\section{Las metáforas que guían la práctica editorial: la torre, el territorio y el triunvirato}

E1 18 de abril de 1997 se entregó en la Casa de Poesía Silva el Premio José Asunción Silva a la Crítica Literaria a Hernando Valencia Goelkel (Valencia, 2018a, p. 21). Rincón no pierde la oportunidad de ironizar sobre este hecho al afirmar que, en este caso, difícilmente habría podido decirse: nace una estrella. Las particularidades de este premio, que se entregó en una única ocasión y en una etapa más que avanzada de la carrera crítica de Valencia Goelkel, permiten sospechar nuevamente sobre el estado del archivo, pero, más aún, de la categoría dada a Valencia Goelkel como autor. Es en este momento en el que se vuelve relevante otra de las metáforas empleadas por Rincón: la torre.

Si se acepta que los autores no preexisten a sus obras, bien puede entenderse que la fijación de una obra (el ordenamiento de un archivo, la concepción de los criterios que guían la ordenación temporal de un corpus) tiene una consecuencia definitiva: la construcción de un autor. Si las metáforas del trayecto y piedra miliar nos habían 
servido anteriormente para pensar las tareas de disposición y ordenamiento del material escrito, la imagen de la torre deberá servir ahora para comprender el propósito de dicho trabajo. En palabras de Rincón, "El efecto principal de unir un nombre con un conjunto de textos es dar lugar a conceptos de autor y de obra, hasta el caso límite de la construcción del autor a partir del legado, de su transmisión, recepción y efecto" (en Valencia Goelkel, 2018a, p. 21). La torre es, pues, la metáfora de la conservación. Torres en lo absoluto inexpugnables, si se tienen en cuenta los azares de los archivos en el país, la lentitud desafiante del reconocimiento y, en fin, la constante y omnipresente amenaza de la muerte y el olvido. Pero ¿qué tan débil?, puede uno preguntarse. Algo de fuerza y de vitalidad habrá de tener (¿es lo que queremos creer?), si es que en verdad se trata de, como dijo Sanín Cano, un "acervo de conocimientos", un "cúmulo de ideas y sentimientos transmitido por una generación a otra”. Anotación al margen: ¿habrá que situar estos libros en forma de torres en todas las bibliotecas para no olvidar que su lectura representa la participación en el ejercicio de construcción de la crítica literaria en Colombia?

En este juego entre el olvido y la memoria (donde la memoria suele llevar la peor parte) Rincón participa como editor, pero más aún, como crítico que valora con el altisonante nombre de "Triunvirato" a la tríada conformada por Sanín Cano, Téllez y Valencia Goelkel. ¿Última rebeldía del crítico contra el paso del tiempo? Solo son rebeldía y humanismo el resistir a la muerte, diría Téllez. Lo cierto es que mal haría en verse la cuestión del Triunvirato como la representación arrogante de una tríada masculina en la que confluyen un conjunto de privilegios, más todavía si el mismo Rincón indica, con modestia, que se trata de un tópico, pero no el de la entronización de una tradición crítica, sino aquel más dinámico que representa el proceso mismo de formación de tradición, la erección de piedras miliares.

La metáfora de las piedras miliares nos regresa a la idea del territorio, última metáfora que debe explorarse para comprender la aproximación de Rincón a la obra de Valencia Goelkel. Si la estrategia temporal había dado enormes réditos con el trabajo de elaboración de la obra de Hernando Téllez, donde cada una de las periodizaciones propuestas se traslapan con episodios de la historia política, será la idea del territorio, con su evidente carácter espacial, la que determine la división hecha de la obra y la vida de Valencia Goelkel. Esto es posible si se piensa su transitar de Bogotá a Madrid, de Mito a Cromos, de Eco al Boletín Cultural y Bibliográfico; su trasegar por 
instituciones sanctas, como los despachos del Palacio de Bolívar, y non sanctas, como la editorial Norma.

\section{El crítico gaviero}

Los diferentes territorios atravesados por Valencia Goelkel tienen algo en común: su propensión al cosmopolitismo (su desterritorialización, curiosamente). Ahora bien, aunque perteneció como lector a todo el orbe, su vida estuvo entre Madrid y Bogotá. Según Rincón, "la imagen primera que se hizo de sí mismo y proyectó Valencia Goelkel fue entonces la de un conector-mediador literario, con sendas selecciones de novísima poesía colombiana, dada a conocer en Madrid, y española, presentada como primicia absoluta, en Bogotá” (en Valencia Goelkel, 2018a, p. 54). Tiene, por lo mismo, especial significado el detalle con el que Carlos Rincón describe los años madrileños de Valencia Goelkel, que viajó gracias a la protección de Gilberto Alzate Avendaño. En esa ciudad encontraría, entre lecturas y juergas, la fértil amistad de Cote Lamus, Gaitán Durán y Caballero Bonald.

Los artículos de Téllez "Problemas de la nueva poesía", "Alegato sobre la poesía"y "Más sobre la poesía” permiten ponderar la relevancia de estas relaciones trasatlánticas, en las que, con más o menos veleidades, se dibujó la figura de la poesía colombiana de mitad de siglo. Junto a la presencia omnímoda de Antonio Machado, Juan Ramón Jiménez y Federico García Lorca, son determinantes la agencia y el protagonismo que adquirieron Jorge Gaitán Durán y Cote Lamus en este proceso. Por lo mismo, y no solo por los ecos falangistas en la admiración de Alzate Avendaño (benefactor de Valencia Goelkel) por la "madre patria", puede decirse que la juerga madrileña de Valencia Goelkel fue, hasta cierto punto, un asunto de Estado para la literatura colombiana.

Pasemos ahora a las cuestiones relacionadas con su oficio crítico. Por haber desarrollado una actividad ininterrumpida como editor, traductor y gestor cultural, bien puede pensarse la figura de Valencia Goelkel a través de la imagen del gaviero, a Mutis cara. El lugar privilegiado que ocupó como editor y traductor de las publicaciones culturales más importantes de la segunda mitad de siglo xx en Colombia, las revistas Mito y Eco, le ofreció acceso a una ingente cantidad de información que había consumido y procesado con la ansiedad que permiten suponer jornadas recurrentes de nueve de la mañana a once de la noche. Gaviero, también, merced a la voracidad de su apetito literario. 
Ahora bien, si en la superficie del territorio crítico de Hernando Valencia se encuentran los roles que asumió como mensajero en las redes culturales del país, en el nervio de su trabajo como escritor se encuentra la forma escogida para comunicar su pensamiento. A ella podemos llegar atendiendo a un hito en su trabajo como crítico: la traducción del libro de Steiner In Bluebeard's castle (1971). Supuso un desafío esta empresa toda vez que, para terminarla a cabalidad, Valencia Goelkel se impuso la tarea de conocer en su totalidad la obra de Steiner y, de paso, leer aquellos autores con los que el propio autor mantenía diálogo constante. Uno de estos autores fue Georg Lukács, en cuyo estudio Über Wesen und Form des Essays desarrollaba la idea de la visión ensayística del mundo (Valencia Goelkel, 2018b, p. 78). El comentario de Rincón a propósito resulta esclarecedor:

El ensayo era para Lukács aquella "forma" con la que el ensayista - el crítico- siempre trataba de los últimos interrogantes acerca de la vida, y sin embargo siempre lo hacía como si "hablara solo de imágenes y de libros". Por eso el ensayo se ocupaba, ciertamente, de algo que ya había recibido forma: literatura, arte, argumentación. Pero en todas ocasiones en una forma que llevaría de la obra particular, del poema, hacia algo que era, para Lukács, mucho más grande y complejo que todos los poemas: la Poesía. Respondiendo a su "forma y esencia", el ensayo solo apuntaría a esto: a incrementar las posibilidades de vivirlos. Pues si el ensayo era siempre un tribunal, lo propio de él consistiría en que ni el juicio ni la evaluación son lo que cuenta. Es el proceso de decidir, de manera que el ensayo es la "forma" por excelencia para ocuparse de lo pasajero, lo transitorio, lo efímero. $\mathrm{Su}$ "forma" no apunta hacia la obra sino a una vida capaz de asumir las experiencias que pueden hacerse con las obras de arte (en Valencia Goelkel, 2018b, p. 80).

El desarrollo de una visión ensayística del mundo, capaz de ampliar la experiencia que se tiene de las obras de arte y, en último término, de los interrogantes de la vida, es la tarea que permite articular el trayecto de Hernando Valencia Goelkel y comprender lo específico de su ejercicio crítico. Característico es de sus escritos el que tengan como título apenas el nombre del autor tratado y que, sin falta, ofrezca al lector un juicio concluyente. Este puede ser halagador, como en el caso del escritor canadiense: "Ondaatje fragua un mundo que no pudo haber conocido; ese mundo es, según las veleidades del lector, arrebatadoramente realista o deleitosamente fantástico. Pero cualquiera de estas dos versiones reconoce que el cuarteto formulado por Ondaatje constituye una lectura memorable" (Valencia Goelkel, 2018b, p. 381). O bien puede defenestrar el libro, como ocurre en estas palabras a propósito de La lentitud (1994): "Más inocente que nunca, el lector termina preguntándose qué llevó a Kundera a ofrecernos, a estas horas de la vida, este plato de posmo- 
dernismo recalentado" (Valencia Goelkel, 2018b, p. 377). En un medio crítico en el que la actividad del ensayista suele reducirse a un elaborado espaldarazo diseñado para evitar posibles discordias, no dejan de ser emocionantes los casos de negatividad crítica.

Sin embargo, como explica Rincón, el ejercicio ensayístico no consiste en el veredicto, sino en el enriquecimiento de la experiencia vital a partir del arte, en la adquisición de un renovado punto de vista y en el proceso de llegar a un juicio. En este camino van muchos de los ensayos de Valencia Goelkel; a propósito, estas palabras sobre el escritor británico: "Por eso Kipling no es el cantor de un mundo feroz y abolido, sino que es contemporáneo de quienes creemos, acaso con excesiva candidez, vivir en una época posimperial” (p. 450). Así, muchos de sus ensayos son un esfuerzo de comprensión que se mueve con flexibilidad entre la determinación de una poética o una corriente literaria y la reflexión a propósito del curso histórico de la literatura y la historia en su conjunto, de los que "Divagaciones sobre el escritor hispanoamericano" (Valencia Goelkel, 2018a, p. 442) y "La mayoría de edad" (p. 607) son un excelente ejemplo.

"La mayoría de edad" merece destacarse por dos razones: primero, por el proyecto editorial en el que fue incluido y, segundo, por su lugar en una de las discusiones críticas centrales de los años setenta: el proceso de autonomización de la literatura latinoamericana. Este artículo de Valencia fue una de las contribuciones colombianas al libro América Latina en su literatura, coordinado por César Fernández Moreno y que parte del proyecto de la Unesco “América en su Cultura”. En este histórico volumen participaron críticos de la literatura y la cultura como el mexicano José Luis Martínez, los uruguayos Mario Benedetti y Emir Rodríguez Monegal, los cubanos Severo Sarduy, Roberto Fernández Retamar y José Lezama Lima, los argentinos Juan José Saer y Noé Jitrik, y los brasileros Haroldo de Campos y Antônio Cândido. Confirmando su cosmopolitismo, el aporte de Valencia Goelkel fue el último de la primera parte, titulada "Una literatura en el mundo", cuya función en el volumen es situar la literatura del continente en el contexto de la literatura universal. La segunda parte llama también la atención, pues titulándose "Rupturas de la tradición" ofrece trabajos en los que se formulan explicaciones a propósito de la originalidad de las literaturas americanas. El escrito de Valencia Goelkel, que se ocupa de la cuestión de la autonomía, es, pues, una bisagra entre ambos capítulos, toda vez que interviene en una de las arenas más 
exigentes en la historia de la crítica literaria latinoamericana de siglo xx. Ángel Rama, Emir Rodríguez Monegal, Antônio Cândido, Rafael Gutiérrez Girardot, Roberto Fernández Retamar y prácticamente todos los críticos latinoamericanos de la época tienen hipótesis a propósito de cómo se habría desarrollado el proceso por el cual la literatura latinoamericana habría dejado de ser epigonal con respecto a la literatura española, y cómo se habría configurado una tradición propia capaz de darle sentido a sus obras y de permear las prácticas literarias de otros sistemas literarios. Esto es, pues, lo que señala Valencia Goelkel con la metáfora orgánica de "la mayoría de edad".

De Baldomero Sanín Cano, el cosmopolitismo y la pertenencia declarada a todas las tradiciones sin cortedad de miras; de Hernando Téllez, la capacidad pedagógica para discutir de manera abierta, sin prejuicios y en la palestra pública... ¿de Valencia Goelkel? La libertad que da la "irresponsabilidad” (Valencia Goelkel, 2018a, p. 628), y la “ironía” (p. 623), que son, en la lectura del proceso de la literatura latinoamericana que presenta en "La mayoría de edad", las grandes conquistas culturales de la tradición literaria latinoamericana que tienen en Borges su punto de inflexión. Esta dimensión infantil recuperada ofrece una visión fresca de la creación artística en la que la capacidad de reformar la realidad prevalece sobre el pesimismo asociado al proceso económico de la región.

Para continuar, importa señalar sus trabajos sobre Evelyn Waugh (Valencia, 2018b, pp. 83-84) y Malcolm Lowry (pp. 34-39), Cesare Pavese (pp. 83-89) e Isaac Babel (pp. 20-34), pues no solo le valieron la desconfianza sempiterna del Partido Comunista, sino un lugar indiscutible como comentarista y difusor de la literatura mundial en el medio colombiano. En todo caso, las oposiciones del medio y la fragilidad lamentable de las empresas culturales que conocieron la actividad de Valencia Goelkel dejan el sinsabor de las instituciones que, por no resultar rentables, desaparecen cada tanto. Entre estos fantasmas surge la pregunta que Rincón formula en diferentes ocasiones: ¿cuál era la gran empresa que habría consolidado todos los años de preparación y trabajo de Valencia Goelkel?

En conclusión, en este trabajo se han comprendido las ediciones de las obras críticas de Hernando Téllez y Hernando Valencia Goelkel a partir de un conjunto de metáforas, como las de torre o piedra miliar, entendidas como formas de hacer operaciones concretas sobre la memoria. Siguiendo los estudios de Sánchez Lopera (2012), puede decirse que Rincón hace descansar su trabajo crítico sobre opera- 
ciones en las que se asocian elementos dispares. En este caso, se han encontrado vínculos entre su obra crítica y su trabajo como editor, partiendo del uso de metáforas como estrategias de organización de información. Dado que comparten entre sí su carácter topográfico, no es difícil ver en ellas un intento de ars memoriae de la crítica literaria colombiana, de buen augurio para una disciplina proclive a negarse a sí misma. Para decir más, la explicación de cómo sucede este ejercicio de memoria se relaciona de manera específica con los críticos estudiados. La lectura propuesta consiste en afirmar que los críticos fueron elegidos en virtud del modelo de crítica que representan, Téllez, una crítica pedagógica y polémica, y Valencia Goelkel, una crítica cosmopolita y abierta a la ironía y la irreverencia.

Estudios posteriores pueden problematizar la noción misma de modernidad. Siendo una de las discusiones centrales del periodo estudiado, importa revisar si el corpus puede ser reelaborado desde una perspectiva crítica del "marco de referencia de la modernidad" (López, 2018, p. 68), siguiendo los estudios que Carlos Arturo López ha adelantado para la historia de la filosofía en su libro El terreno común de la escritura. Una bistoria de la producción filosófica en Colombia 1892-1910.

Para terminar, quisiera remitirme a los pasajes en los que Rincón revisa la crítica de cine hecha por Valencia Goelkel. En estos pasajes se siente con intensidad la amistad y la relación sentimental que vinculó a Valencia Goelkel y a Rincón. Estas últimas palabras de Rincón cumplen la más noble tarea del crítico en la medida en que son, si se quiere, el testamento de una amistad. Los lectores, beneficiados por la escritura, reciben en donación la memoria de dos vidas dedicadas a la crítica del arte y la cultura, en definitiva, un mundo que, sostenido por la admiración, la amistad y el amor (no el eterno, sino el que se encuentra sometido a la ley de las intermitencias del corazón) quizás no fue lo suficientemente estable, pero sí lo suficientemente estimulante como para mantener una existencia atenta y dejar huella tras de sí, cuando no, una que otra piedra miliar, acaso una torre, que no es poca cosa.

\section{Referencias bibliográficas}

Castaño, Á. (2017). El insomnio de la crítica. Recuperado de https://www.revistaarcadia.com/impresa/ literatura/articulo/critica-en-colombia-esta-pasando-por-una-crisis/65677/

Escobar, J. (2019). La crítica cultural y literaria de vanguardia de Carlos Rincón. Literatura: teoría, historia, crítica, pp. 267-285. 
Ginzburg, C. (1999). Indicios: Raíces de un paradigma indiciario. En C. Ginzburg, Mitos, emblemas e indicios (pp. 138-175). Barcelona: Gedisa.

González Keelan, S. (2018). Hernando Téllez (1908-1966): apuntes para una biografía. Revista Iberoamericana LXXXIV (262), pp. 25-41. DOI: https://doi.org/10.5195/reviberoamer.2018.7575

Henderson, J. (2006). La modernización en Colombia. Los años de Laureano Gómez 1889-1965. Medellín: Editorial Universidad de Antioquia.

López, C. (2018). El terreno común de la escritura. Una historia de la producción filosófica en Colombia 18921910. Bogotá: Pontificia Universidad Javeriana.

Montoya, P. (2007). Contornos de la crítica literaria en Colombia. Literatura: teoría, bistoria, crítica 9, pp. 403-411.

Rincón, C. (2010). Memoria y nación: una introducción. En L. Gómez, S. González de Mojica y C. Rincón (Eds.). Entre el olvido y el recuerdo. Íconos, lugares de memoria y cánones de la bistoria y la literatura en Colombia (pp. 26-61). Bogotá: Editorial Pontificia Universidad Javeriana.

Sánchez Lopera, A. (2012). Carlos Rincón y la crítica de la voluntad de verdad. Una pragmática de la crítica literaria. Estudios de Literatura Colombiana 30, pp. 81-107.

Sanín Cano, B. (1987). El oficio de lector. Caracas: Biblioteca Ayacucho.

Silva, R. (2005). República Liberal, intelectuales y cultura popular. Medellín: La Carreta.

Suescún, N. (2005). Hernando Valencia Goelkel: 50 años del mito de Mito. ciudadviva.gov.co, diciembre. Alcaldía Mayor de Bogotá. Recuperado de https://www.ciudadviva.gov.co/diciembre05/magazine/5/index.php

Téllez, H. (2016). Crítica literaria I 1936-1947, edición establecida, introducida y anotada por Carlos Rincón. Bogotá: Instituto Caro y Cuervo.

Téllez, H. (2017a). Crítica literaria II 1948-1956, edición establecida, introducida y anotada por Carlos Rincón. Bogotá: Instituto Caro y Cuervo.

Téllez, H. (2017b). Crítica literaria III 1957-1967, edición establecida, introducida y anotada por Carlos Rincón. Bogotá: Instituto Caro y Cuervo.

Valencia Goelkel, H. (2018a). Crítica literaria 1955-1976 Tomo I, edición a cargo de Carlos Rincón. Bogotá: Instituto Caro y Cuervo.

Valencia Goelkel, H. (2018b). Critica literaria 1977-1997 Tomo II, edición a cargo de Carlos Rincón. Bogotá: Instituto Caro y Cuervo. 